CENTRE FOR ECONOMIC POLICY RESEARCH

Australian National University

DISCUSSION PAPERS

THE GETTING OF MACROECONOMIC WISDOM

\author{
Adrian Pagan \\ Economics Program \\ Research School of Social Sciences \\ Australian National University
}

DISCUSSION PAPER NO. 412

October 1999

Presented as one of the

Invited Lectures on Macroeconomics

$12^{\text {th }}$ World Congress of the

International Economic Association

Buenos Aires August 1999

ISSN: 1442-8636

ISBN: 0731522761 


\section{CONTENTS}

Page

$\begin{array}{lll}\text { Abstract } & \text { i }\end{array}$

1. Introduction 1

2. Summarising the Data 2

2.1 Summarising the Evidence on a Single Series 4

2.1.1 Linear models of the conditional mean $\quad 6$

$\begin{array}{ll}\text { 2.1.2 Models of volatility } & 7\end{array}$

2.1.3 Non-linear models for the conditional mean $\quad \mathbf{8}$

2.1.4 Visual evidence and parameteric statistical models

2.2 Summarising the Evidence on Multivariate Series 13

2.2.1 Multivariate regressions $\quad \mathbf{1 3}$

2.2.2 VARs 14

2.2.3 Vector error correction models $\quad \mathbf{1 5}$

2.2.4 Non-linearities in VARs $\quad \mathbf{1 5}$

3. Interpreting the Data 16

3.1 Interpreting Univariate Series $\quad 18$

3.2 Interpreting Multivariate Data 20

3.2.1 SVARs $\quad \mathbf{2 0}$

3.2.2 Academic calibrated models $\quad \mathbf{2 3}$

3.2.3 Calibrated policy models $\quad \mathbf{2 8}$

$\begin{array}{lll}\text { 4. Conclusion } & 31\end{array}$

$\begin{array}{ll}\text { Notes } & 33\end{array}$

$\begin{array}{lr}\text { References } & 34\end{array}$ 


\begin{abstract}
The paper discusses a number of trends in the use of macro-economic models for acquiring information about the macro-economy. It is argued that a fundamental distinction should be drawn between models that are constructed to summarise the data and those which are used to interpret the data. By and large the former are statistical and so are judged on the basis of how well they fit the data. Nevertheless, while we have leaned a lot about the nature of macroeconomic data from the large number of statistical models that have emerged to carry out this task, we demonstrate that some of the perceived features may not stand up to a sustained investigation. In particular, it is argued that graphical analysis can often throw doubt upon certain conclusions stemming from formal statistical inference.
\end{abstract}

The second part of the paper turns to models that have been set up with the aim of interpreting macroeconomic data. These are economic in nature, and represent stories that we tell about economic interactions with a view to understanding the origin of observable data characteristics. Given this orientation, goodness of fit is not regarded as the only criterion for assessing their success. Consequently, issues arise over how one can compare such models. A range of methods has evolved for ascertaining whether the proposed story is a good description of the data. We review these methods as well as making some suggestions about how one might improve on them. 


\title{
The Getting of Macroeconomic Wisdom ${ }^{1}$
}

\author{
Adrian Pagan \\ Research School of Social Sciences \\ AUSTRALIAN NATIONAL UNIVERSITY
}

The beginning of Wisdom is this: get wisdom and whatever you get, get insight,

Prov, 4:7, RSV.

\section{INTRODUCTION}

As the proverb says it is wisdom that we want and much of what we do is aimed at acquiring it. On reflection, the acquisition of wisdom is a two stage process. In the first stage ideas are accumulated and explored; in the second those ideas that have withstood the 'experience test' are retained and recounted to others as insights. Macroeconometric modelling involves the same dichotomy and it was one that was fruitfully exploited by the Cowles Commission researchers. In the first stage, evidence needs to be assembled and summarized in a convenient and meaningful way while, in the second, effort is devoted to interpreting the evidence through a set of principles or theories. ${ }^{2}$ For the Cowles Commission the two stages were represented by the construction of a reduced form and a structure. Thus the distinction has a distinguished history in econometrics. However, all too often it has been ignored and the two stages are blurred together. Indeed, this blurring of the two categories goes back to the very beginnings of macroeconometrics and even features one of the most prominent members of the Cowles Commission, Tjalling Koopmans. The occasion was his famous critique of Burns and Mitchell's (1947) work on the business cycle. Although Koopmans (1947) seems to recognise that the latter are attempting to summarise the 
available data on the business cycle, he quickly complains that one needs theoretical models to interpret the data, and so the steps of summarising and interpreting the data are rolled together in his critique. Indeed, the very title of his paper, 'Measurement without Theory', suggests that the two are one. I will place great emphasis on the distinction in this paper — and it actually provides headings for each of the sections that follow - as I believe that much more progress can be made by hewing to the division than trying to amalgamate the two stages into one. Moreover, important developments in econometrics in the past decade, namely the development of indirect estimation methods, as in Gourieroux et al (1993), Smith (1993) and Gallant and Tauchen (1996), have this distinction at their core.

\section{SUMMARISING THE DATA}

Consider first how one would want to summarise the data. On one level this is an easy question to answer. It is hard to avoid the impression that the exploration of issues in applied macroeconomics has always had a strong visual element to it. A very good example would be the Phillips curve, in which the rate of change of wages and unemployment were cross plotted. Another would be the treatment of the relation between money growth and inflation in Lucas (1980). Indeed, some think that such evidence has been the most influential type in stimulating thought about the macroeconomy and in influencing policy actions - Summers (1991). Certainly, it does seem likely that the early history of applied macroeconomics largely involved an inspection of graphs, Such evidence can however be tricky to use. Accordingly, the development of statistical methods was greeted with great 
enthusiasm, since it seemed to promise automatic ways of summarising evidence. It is true that what one saw in graphs of a set of variables might be represented to some degree with the sample moments of the series - the means showed the levels, the variances captured volatility, and the correlations performed a similar function to cross plotting, although the information is rarely exactly preserved. A good example of the latter occurs in the case of correlation, which tended to be treated as involving a linear relationship between two variables, even though a graph might have highlighted a non-linear one. But there was no doubt that many pieces of information were reduced to a much smaller and manageable set, either in the form of a regression output or through parametric indices such as volatility, duration of a business cycle etc.

When one comes to data summary two questions have often been asked about the method used: is it complete or incomplete and is it useful for answering the question being addressed? The first two moments of a time series generally failed the completeness test since they did not capture the degree to which the series had some temporal dependence. Eventually, the deficiency was corrected by a computation of the autocorrelation function and the extended set of first and second moments was taken to describe the important characteristics of a time series. The second requirement is more nebulous and, even today, one can see wide disagreement over what are the most useful ways of summarising data to address a specific question. Some of this disagreement really stems from a failure to isolate the summarisation and interpretation phases. In my opinion the summarisation stage is largely one that involves statistics and revolves around the selection of the best 
statistical models of a series; economics really only enters into it through a naming of what variables it is that one seeks evidence on. Of course, the latter is not a trivial issue and the selection of a set of variables that is too narrow may well prejudice the answers obtained.

\subsection{Summarising the Evidence on a Single Series}

It is interesting to ponder a little more upon the theme of how to translate visual evidence into quantitative measures by considering the topic of the business cycle. One might well argue that it was the business cycle that gave birth to the study of macroeconomics and, even today, is responsible for a large fraction of the work done in this area. The business cycle involved the economy traversing periods of prosperity and periods of misery and these periods could be seen quite clearly when one plotted a series of industrial production or unemployment over time. Indeed it was apparent that these periods could be marked off by locating the turning points in the series. Once (say) a peak was found the period immediately to the left (on a graph against time) could be called an expansion and that to the right a contraction. Consequently, if one wanted to study the business cycle, the obvious way to summarise the data was through turning point information and not moments. This simple idea was how Burns and Mitchell compressed much macroeconomic data into measures of the business cycle; it was a methodology that was meant to describe what one saw visually through a set of numbers characterising the average cycle e.g. its duration, its amplitude etc. Burns and Mitchell attempted to provide a complete and useful summary by distinguishing many stages of the cycle that they could see in the graphs. If 
you wanted to talk about the ups and downs of the economy in a straightforward manner these were the obvious and most useful measures. Even today we see their successors, NBER dates, widely used in macroeconomic discussion and analysis. It's clear that if you all you wanted to ask about economic activity was its volatility then you wouldn't find Burns and Mitchell's measures of much use. But the question being asked by policy makers was whether they could change the shape of the graph of economic activity and so it was natural that one focus upon what one saw in it.

The focus upon the business cycle provided by Burns and Mitchell's methodology was essentially a graphical one. As mentioned earlier the development of statistical science initiated a move from graphical displays to methods of summarising the data which posed the task as one involving the estimation of a set of parameters - means, variances etc. Academics were naturally attracted to the latter, since the method promised both replicability and the ability to explore other ways of performing the data summary by converting it to a question of the design of new estimators of the parameters e.g. the aggregate inflation rate might be measured as either the mean or the median of the inflation rates of individual commodities. By making assumptions about the nature of $y_{t}$ so as to study the properties of alternative estimators one could describe the circumstances under which each would be appropriate. Moreover, the possibility was also raised that simple parametric models might be capable of summarising a vast amount of information in a succinct way e.g. while an $A R(1)$ of the form

$$
y_{t}=\rho y_{t-1}+e_{t}
$$


has an infinite number of autocovariances, they depend upon the single parameter $\rho$, and so a complete graph of the autocovariance function might be represented by a single parameter.

\subsubsection{Linear models of the conditional mean}

The simplification principle was central to the work of Box and Jenkins (1970). Those applying the latter's techniques to macroeconomic data found that such series could be well represented with fairly simple forms, sometimes surprisingly so. A classical example was the finding that the log of GDP $y_{t}$ could be well represented by making its growth rate, $z_{t}=\Delta y_{t}$, either an $A R(1)$ or an $\operatorname{AR}(2)$

$$
z_{t}=\rho_{1} z_{t-1}+\rho_{2} z_{t-2}+e_{t}
$$

i.e. the time dependence was of a fairly simple form. What was perhaps more surprising, given that the second order process had been selected to capture the 'business cycle', was that the roots of the polynomial $\left(1-\rho_{1} L-\rho_{2} L^{2}\right)=0$ were real and not complex (see Pagan (1999) for evidence on this for ten countries). This is a challenging finding for theory construction since, for a long time, textbooks had taught that one needed a complex root $A R(2)$ process to produce the business cycle, and ingenious models had been constructed so as to achieve such an outcome; indeed Frisch's famous 'rocking horse' analogy rested on this mechanism as the way of producing a cycle.

The conflict between theory and fact shown in this example is an interesting one as it is not an isolated case. It has engendered two responses; one is that 'theory is ahead of measurement' and there is something wrong 
with the data. A second is to argue that the definitions being used are at fault, in this instance the identification of a business cycle with the nature of the roots of an $A R(2)$ process. What we know about the cycle, and what macroeconomists endlessly quote, are results from NBER and Burns and Mitchell, and these all describe a cycle through its turning point behaviour. In fact an $A R(1)$ process such as (1) will produce turning points in $y_{t}$ with similar frequency to what is seen in the data, provided $\rho_{1}$ is close to unity - see Hess and Iwata (1997a) and Pagan (1997) (for an early view, see Sargent (1979)). None of this discussion should be taken as asserting that there are not complex roots in some macroeconomic series; investment and employment are sometimes counter-examples, but it is rarely true of GDP, and it is that fact which must be accommodated by theorists.

\subsubsection{Models of volatility}

Although simple models such as (1) and (2) proved very effective at characterizing macroeconomic series, they could not capture all the characteristics that were observed. In particular, series of many asset prices showed 'clustering of volatility', in that a run of small or large values of $\left(\Delta y_{t}\right)^{2}$ or $\left|\Delta y_{t}\right|$ were clearly visible in the data. Extensions of models like (1) and (2) were deemed necessary and Engle's (1982) development of the ARCH class of models provided a good way of parameterising this evidence. After that development it became the norm for describing this feature of the data. In the ARCH model $e_{t}=\sigma_{t} \varepsilon_{t}$, where $\varepsilon_{t}$ was n.i.d. $(0,1)$ and $\sigma_{t}$, the conditional standard deviation, was related linearly to $\mathrm{e}_{\mathrm{t}-1}^{2}$. Many alternative mappings of $\sigma_{t}$ into $\left\{e_{t=1}\right\}$ have been proposed -see the surveys in Pagan (1996) and 
Bollerslev et al (1994). Lately the stochastic volatility class of models, in which $\sigma_{t}$ is made a function of some i.i.d. random variable $\eta_{t}$ which is uncorrelated with $\varepsilon_{\mathrm{t}}$, has become popular, as it represents the analogue of (1) but applied to the second rather than first moment. There can be little doubt about the existence of conditional volatility in asset prices and that it is a feature which must be accounted for in theorising with any models that are capable of producing predictions about asset price behaviour.

\subsubsection{Non-linear models for the conditional mean}

Because financial prices generally had $\rho=1$ one was effectively substituting $\left(\Delta y_{t}\right)^{2}$ or $\left|\Delta y_{t}\right|$ for $y_{t}$ as the object to plot and for which autocorrelation functions etc should be computed. But the resulting process in re-defined variables could still be thought of as linear ones. Within the linear class one can play around with lag lengths but, by and large, such investigations provided little that was useful in the way of summarising the data. The urge to complexify is a strong one though and gradually inquiries arose over whether some nonlinearities might be introduced into the basic models. In the case of the modelling of volatility, such an extension proved to be useful at a very early stage in the development of $\mathrm{ARCH}$ models, mainly because of a feature that had been observed in the data viz. what was termed 'leverage', wherein volatility seemed higher when the market was falling. The seminal work on extending the class of parametric models to capture this effect was that of the late Dan Nelson (1991) and it is incorporated in his EGARCH model. 
The situation is much murkier when it comes to assessing the progress in finding important non-linearities in the conditional means of $y_{t}$ or $\Delta y_{t}$. Many non-linear models have been proposed. A simple example would be Potter's(1995) variant of a threshold autoregression (the SETAR model):

$$
\Delta \mathrm{y}_{\mathrm{t}}=\mathrm{a}_{0}+\mathrm{b}_{0} 1\left(\Delta \mathrm{y}_{\mathrm{t}-1}<0\right)+\left[\mathrm{a}_{1}+\mathrm{b}_{1} 1\left(\Delta \mathrm{y}_{\mathrm{t}-1}<0\right)\right] \Delta \mathrm{y}_{\mathrm{t}-1}+\mathrm{e}_{1 \mathrm{t}}
$$

Other are the asymmetric persistence model of Beaudry and Koop (1993), the 'overheating' model of Pesaran and Potter (1997), and the switching regime structures in Hamilton (1989) and Sichel (1994).

All of the models described above are relatively simple to understand and, consequently, represent quite attractive extensions to the basic linear models that have been the norm in summarising the data. The question that has to be asked though is whether they summarise important characteristics of the data. It is true that statistical tests tend to reject the linear model in favour of non-linear ones but it is also well-known that any regression can be very sensitive to a few influential points in the data and there has been little work done in exploring the origin of the non-linearity in the data. Hess and Iwata's conclusion that

\section{Despite their appeal nonlinear time series models are no better at replicating} the business cycle features of the data than a simple ARIMA $(1,1,0)$

(1997a: 442)

points to the need to make a more detailed investigation of the phenomenon.

A simple way of assessing these models is to consider what the prediction of $\mathrm{E}\left[\Delta \mathrm{y}_{\mathrm{t}} \mid \Delta \mathrm{y}_{\mathrm{t}-1}\right]$ would be from linear and non-linear models compared to what is implied by the data. Since these models produce strictly stationary processes for $\Delta \mathrm{y}_{\mathrm{t}}, \mathrm{E}\left[\Delta \mathrm{y}_{\mathrm{t}} \mid \Delta \mathrm{y}_{\mathrm{t}-1}\right]$ exists, even if the model under examination 
involves higher order lags. Figure 1 cross plots $\Delta \mathrm{y}_{\mathrm{t}}$ and $\mathrm{E}\left[\Delta \mathrm{y}_{\mathrm{t}} \mid \Delta \mathrm{y}_{\mathrm{t}-1}\right]$ against $\Delta \mathrm{y}_{\mathrm{t}-}$ 1, where $E\left[\Delta y_{t} \mid \Delta y_{t-1}\right]$ is constructed from a both a linear model and the asymmetric persistence model of Beaudry and Koop $(\mathrm{BK})^{3}$. The conditional mean of the non-linear model was estimated non-parametrically by generating 3000 observations from the BK model, with the parameters being set to those values given in the appendix of Hess and Iwata (1997a). It is clear that, for the bulk of the data, there is little difference between the linear and non-linear formulations. Moreover, if one thinks of a recession as two consecutive periods of negative growth, then it is clear that the BK model is not very good at predicting that event. This outcome is probably what accounts for the conclusions reached above on the failure of these models to add much to the explanation of the cycle. The probability of occurrence of a second negative growth rate owes more to the volatility of shocks than to any relationship with the past.

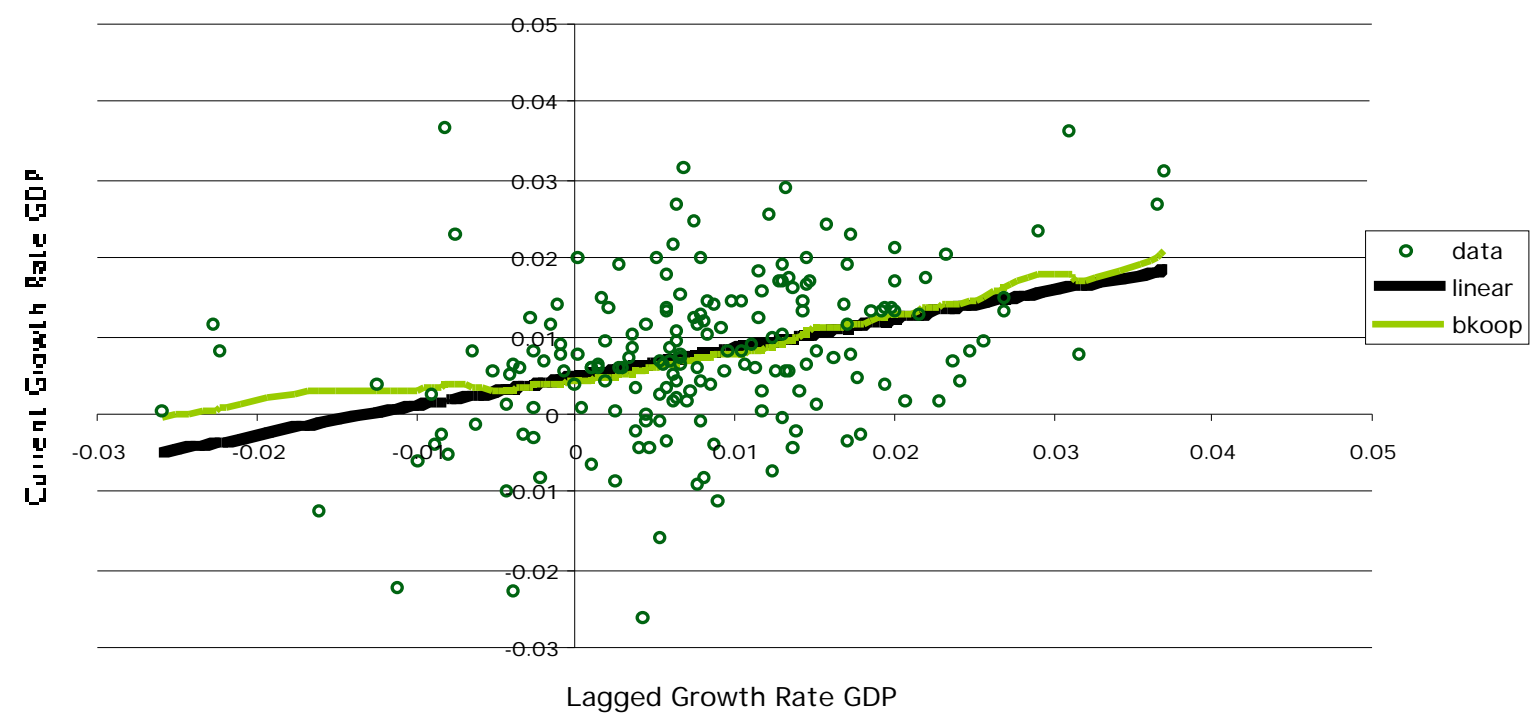

Figure 1: Conditional Means of Beaudry-Koop and Linear Models 
Thus, despite the fact that, on purely statistical criteria such as likelihood ratio tests etc, the non-linear models are preferred, it is difficult for me to subscribe to the notion that we need to spend a large amount of time trying to construct theories to replicate the evidence on output as viewed through the non-linear filter. This may not be the case for other series such as employment and investment but there has been much less work characterising any non-linearities in such series.

\subsubsection{Visual evidence and parametric statistical models reconsidered}

There are other features of the data that can be visually appreciated but which may be difficult to summarise in a parametric statistical model. One of these relates to the shapes of expansions. In a stylised way an expansion might be thought of as following the hypotenuse of a triangle connecting the trough and peak of the phase. In practice expansions tend to depart from this triangular shape. Mostly the area under the actual expansion path exceeds that from a triangle by a significant margin i.e. expansions tend to have an 'acceleration' element to them, something that is well recognised in policy circles, where it is often said that at some point in an expansion one will be surprised by its speed. An alternative way of looking at the shape issue is that emphasised by Sichel (1994); early in the expansion average growth exceeds what it is late in the expansion, producing a curved shape to expansions. One can construct an index by comparing the two areas. Designating the duration of the i'th phase as $D_{i}$ and the amplitude as $A_{i}=\Sigma_{j=t p+1, t p+D(i)} \Delta y_{j}$, where $j$ is the turning point marking the beginning of the phase, the product $C_{T i}=.5\left(D_{i}^{*} A_{i}\right)$ is the area of the 'triangle approximation' to the cumulated movements over the 
phase. The actual area under the path followed in the phase is $C_{i}=$ $\left[\Sigma_{\mathrm{j}=\mathrm{t}+1, t \mathrm{t}+\mathrm{D}(\mathrm{i})} \Sigma_{\mathrm{k}=\mathrm{t}+1, \mathrm{j}} \Delta \mathrm{y}_{\mathrm{k}}\right]-.5^{*} \mathrm{~A}_{\mathrm{l}}$, leaving the average excess area as $E X_{i}=\left(C_{\mathrm{i}}-\right.$ $\mathrm{C}_{\mathrm{Ti}} / \mathrm{D}_{\mathrm{i}}{ }^{4}$

The index just developed was termed the 'excess' in Harding and Pagan (1999). Consider what this looks like for a phase of duration $D_{i}=3$. Then $\mathrm{A}_{\mathrm{i}}=\Delta \mathrm{y}_{\mathrm{tp}+1}+\Delta \mathrm{y}_{\mathrm{tp}+2}+\Delta \mathrm{y}_{\mathrm{tp}+3}, \mathrm{C}_{\mathrm{Ti}}=.5^{\star} 3^{\star} \mathrm{A}_{\mathrm{i}}, \mathrm{C}_{\mathrm{i}}=\Delta \mathrm{y}_{\mathrm{tp}+1}+\Delta \mathrm{y}_{\mathrm{tp}+1}+\Delta \mathrm{y}_{\mathrm{tp}+2}+\Delta \mathrm{y}_{\mathrm{tp}+1}+$ $\Delta y_{t p+1}+\Delta y_{t p+2}+\Delta y_{t p+3}-.5^{\star} A_{i}$. Now, letting $\mu_{j}=E\left(\Delta y_{t p+j} \mid D_{i}\right)$, we have $E\left(A_{i j} \mid D_{i}\right)=$ $\mu_{1}+\mu_{2}+\mu_{3}, E\left(C_{T_{i} \mid} \mid D_{i}\right)=1.5^{*}\left(\mu_{1}+\mu_{2}+\mu_{3}\right)$ and $C_{l}=2.5 \mu_{1}+1.5 \mu_{2}+.5 \mu_{3}$, so that $E\left[E X_{i}\right]=\mu_{1}-\mu_{3}$. If the $\mu_{j}$ are all the same then this index would have expected value of zero. In practice, the average values of this index computed using post-war US, UK and Australian GDP data are quite a long way from zero, being $1.1, .7$ and 1.0 respectively (when $\Delta \mathrm{y}_{\mathrm{t}}$ is measured as percentage growth rates). Thus it is clear that, to account for such a phenomenon, one would need the $\mu_{\mathrm{j}}$ to vary. In words, we need the expected growth rates in any phase to differ depending on where we are in the phase. To some extent this phenomenon is captured by the notion of duration dependence, and its presence presents quite a challenge to the construction of theoretical models, which have invariably been constructed without such a phenomenon. Of course, even if the expected value of the index is zero one might find values of it that deviate from zero for any set of realised values for $y_{t}$. To assess the significance of the departure one would need to simulate any proposed model of the cycle and then determine whether the empirical value of the index lies too far out in the tails of the distribution. Many linear and non-linear models of the cycle were simulated in Harding and Pagan $(1998,1999)$ but in all cases one could easily reject the hypothesis that it was possible to get the value of 
the excess found with US data by chance. This was true even for those parametric statistical models which did exhibit some duration dependence, suggesting that the chosen models did not manage to capture that effect very well. To investigate this outcome a little more fully we focus on Sichel's (1994) analysis. He looked at a range of models that might capture this characteristic, one of which was a three state version of Hamilton's model where the three states were meant to distinguish between contractions, moderate- and fastexpansions. Another of his models was a variant of Beaudry and Koop's. Simulations of these two models give an $E(E X)$ of around .2 for the US. Thus, to date, it has been difficult to find a parametric statistical model that would replicate this feature of actual cycles, highlighting the limitations of the parametric approach.

\subsection{Summarising the Evidence on Multivariate Series}

\subsubsection{Multivariate regressions}

When faced with a number of series, data summary is often done through the estimated coefficients of multivariate regressions. Classic examples are the Phillips curve, the correlation between hours and productivity, and growth regressions that relate cross-country growth rates to a large number of variables. Sometimes these relationships incorporate non-linear regression, either through simple functional forms or by using the recurring states way of inducing a non-linearity. In some ways it is surprising that we have not seen more non-parametric methods being used for such data summary e.g. in Barro-type growth-rate regressions the initial condition is assumed to impact linearly upon growth rates, whereas one might have expected that there could be some non-linear response. There has also been some use of factor 
analysis to try to separate data into factors that might be later related to economic variables. For time series, examples of the latter would be Chauvet (1998) for output changes and Chauvet and Potter (1998) for the equity premium, while in cross sections the decomposition is into factors that are local (idiosyncratic), and global.

\subsubsection{VARs}

The Cowles Commission chose to summarise multivariate sets of data through a reduced form in which endogenous variables were conditioned upon the exogenous and predetermined variables contained in a specified structure. There was nothing in this choice however that was specific to time series. As the subject of time series developed in statistics though, the natural strategy was to extend univariate approaches to multivariate series, and this meant a vector of AR processes. The idea seems to have first been proposed by Quenouille (1957). Later, vector ARMA processes became popular in time series analysis, although less so in macroeconomics where, ever since Sims (1980), VARs have been the dominant way of summarising the multivariate dependence seen within the data. The p'th order VAR is

$$
y_{t}=A_{1} y_{t-1}+A_{2} y_{t-2}+\ldots A_{p} y_{t-p}+e_{t}
$$

where $y_{t}$ is an $n \times 1$ vector, $\operatorname{cov}\left(e_{t}\right)=\Omega$, and one could summarise the data with $A_{1}, \ldots, A_{p}$ and $\Omega$. Alternatively, following Sims' ideas, one could write out the MA representation

$$
y_{t}=D_{0} e_{t}+D_{1} e_{t-1}+\ldots
$$


and one might then use the impulse responses $D_{j}$ and $\Omega$ rather than $A_{1}, \ldots, A_{p}$ and $\Omega$ to summarise the data. Most of the available literature which deals with VARs as a way of summarising the data has been concerned with choosing $p$ and imposing some restrictions upon the $A_{j}$ in order to help with forecasting.

\subsubsection{Vector error correction models}

If one feels that the $y_{t}$ processes are I(1), and common stochastic trends are evident among them, then it is known that $1-A_{1}-\ldots-A_{p}$ is singular and the VAR is replaced by an error correction model (ECM) (assuming for convenience that $p=1$ )

$$
\Delta y_{t}=\alpha \beta^{\prime} y_{t-1}+e_{t}
$$

Now the data is summarised by $\alpha$ (the loadings), $\beta$ (the co-integrating vectors) and $\Omega$, while the MA representation is

$$
\Delta y_{t}=C(L) e_{t}
$$

In the ECM format some combinations of the $e_{t}$ are permanent shocks and others are transitory. An extensive literature has evolved which suggests that there are often fewer stochastic trends than $n$ in the data i.e. the number of permanent shocks is less than $\mathrm{n}$.

\subsubsection{Non-linearities in VARs}

Just as VARs were the obvious extension of univariate models to the multivariate context, one might expect that non-linear VARs would have emerged to parallel the literature on univariate series. In fact, this development has been much slower, probably due to the need to develop 
some computationally tractable forms. To date no particular format seems to have gained favour. One relatively simple method that has had some application involves treating all of the series $\Delta \mathrm{y}_{\mathrm{jt}}$ as being driven by a single common factor $z_{t}$ and to then introduce the non-linearity through the evolutionary process for this factor. In most applications the common factor is not a common trend i.e. the $y_{j t}$ are not cointegrated. Because $z_{t}$ is a univariate process all of the non-linear structures mentioned in section 2.1.3 might be adopted for it, but the most popular approach has been to introduce the nonlinearity through a regime switching format such as Hamilton's (1989) model e.g. Chauvet (1998).

Although the strategy outlined above has some appeal, other types of non-linearity might need to be accounted for. One example would be the possibility that impulse responses show asymmetric behaviour, depending on a particular outcome for some index $\phi_{t}$ e.g. $\phi_{t}$ might be either the sign of the change in a variable - Cover (1992) - or an index indicating whether the economy is in a contraction or expansion phase. Mostly these non-linearities are handled by interacting the index with some of the variables under discussion and it is these multiplicative variables that constitute the nonlinearity. Other types of non-linearity can arise if variables change discretely e.g. as with the Federal Funds target rate set by the FOMC - Hamilton and Jorda (1998) — and certain shifts in policy regimes — Sims (1999).

\section{INTERPRETING THE DATA}

It is in the process of interpreting data, particularly in the context of considering policy options, that economic theory becomes important. Whilst a 
purely statistical summary of the data can be a useful source of 'stylized facts', drawing attention to what needs to be explained, and the statistical models underlying the summary can be useful for forecasting, ultimately one needs to have some way of explaining why the 'facts' are as they are. To do that we construct economic models of the series under investigation with the aim of providing a convincing story about the observed outcomes; as Dawes says

People have a great deal of difficulty appreciating statistical contingency in the absence of a causal story that makes the contingency 'reasonable'. (1999, p. 29)

How detailed this story is depends a great deal upon the nature of the storyteller and the audience he is addressing. Generally, the story we construct is about the behaviour of agents, and for this reason we will refer to these as behavioural models. Behaviour can be described by accounting for how choices are made. The methods to perform the latter task range from introspection through rules of thumb to optimising frameworks.

Three principles need to be abided by when moving to the interpretation stage. First, the story should be about data, and should not just be a story. There is always the danger of the latter occurring, and it is at its greatest when academics become divorced from contact with those working on policy issues. Second, it is imperative that the interpretation step be clearly demarcated from that producing the statistical summary. Identifying a good statistical model for summarising the data should not be confused with the model we wish to use for story-telling. ${ }^{5}$ Finally, even if one is looking only at univariate data, it is important to remember that it is generated from a system, and so some attention needs to be paid to that fact. A failure to 
adhere to this principle occurs most often with multivariate regressions. A classic example would be cross-country regressions involving growth rates in GDP and investment shares, where the two steps are distinguished simply by an attribution of directional causality in the second stage. In this case the system is implicitly completed with a set of strong assumptions about the nature of regressors. Often this fact is not recognised in discussion. As Klenow and Rodriguez-Clare say about growth regressions:

Distressingly Barro and Sala-I-Martin (1995) often use language implying causality, such as writing that an increase in a control variable (with a positive coefficient) 'raises' the growth rate. $(1997$, p. 610)

Even when a system is recognised, as in the Cowles Commission's approach, there can nevertheless be difficulties. Many of those who implemented the Cowles Commission's ideas wrote down a series of structural equations as a statement of the way they saw the system as operating and then deduced a reduced form from that, which they subsequently utilised to summarise the data. There was some flexibility in what they did, in that many behavioural structures could be compatible with a given reduced form, but it is nevertheless the case that the choice of model as the vehicle to summarise the data came from the stories they were trying to tell and not, as I would argue, from the principle of selecting that statistical model which best fits the data.

\subsection{Interpreting Univariate Series}

There is little doubt that the nature of univariate series such as output behaviour, price inflation and asset prices are often used as quick checks on whether the interpretation of the data being offered is a reasonable one. For example, the fact that US GDP growth has positive serial correlation has often 
been used to argue that many $\mathrm{RBC}$ models are incapable of generating the correct process for the path of aggregate economic activity — see Cogley and Nason (1995) and Ramey and Watson (1997) — while the magnitude of the equity premium has also cast doubt upon many models based on simple capital asset pricing principles. Another example would be Nelson's (1998) use of the fact that inflation is a very persistent process to query models of inflation and fluctuations such as that of King and Wolman (1996), since the latter imply relatively weak persistence in inflation. Almost all quantitative economic models do contain predictions about univariate series and so it seems a good strategy to elicit these in a first round assessment. Zellner and Palm (1974) recommended such a strategy quite a while ago.

We have learned a lot from studying such simple comparisons and discovering how models would need to be adjusted to be able to interpret those features of the data. For example, as we noted earlier, volatility clustering in asset prices demands some explanation. Some optimising behavioural models have emerged in which volatility clustering comes from behavioural choices rather than from the nature of the exogenous processes that drive the system, e.g. den Haan and Spear (1998), but the most successful methods seem to be those in which agents are assumed to have rather simple trading strategies e.g. Lux and Marchesi (1999). Perhaps this is not surprising. The volume of literature on 'technical analysis', and the marketing of advice by 'Dow theorists' etc., point to the need to develop heterogeneous agent models in which some traders do not optimise in any clearly defined way but follow rules that are data dependent. 


\subsection{Interpreting Multivariate Data}

\subsubsection{SVARs}

In the past two decades macroeconomics has wholeheartedly adopted the idea of shocks as the driving forces of the economic system, and discussion of their role is either carried out by reference to particular names such as money and supply or to some of their characteristics such as permanent or transitory. Given such a development, it is inevitable that any data will often be interpreted in terms of a set of shocks. In their simplest incarnation most economic models can be written either as a structural VAR (SVAR)

$$
\mathrm{B}_{0} \mathrm{y}_{\mathrm{t}}=\mathrm{B}_{1} \mathrm{y}_{\mathrm{t}-1}+\varepsilon_{\mathrm{t}}
$$

or a 'structural MA'

$$
\mathrm{y}_{\mathrm{t}}=\mathrm{C}_{0} \varepsilon_{\mathrm{t}}+\mathrm{C}_{1} \varepsilon_{\mathrm{t}-1}+\ldots
$$

where $y_{t}$ is now a vector of $n$ variables and there are $k(\leq n)$ shocks $\varepsilon_{t}$ that drive the system. These shocks are assumed to have a covariance matrix $\Sigma$. The SVAR tradition generally views the equations in (8) as embodying some sort of behaviour, but it is rarely precisely defined. In this sense it doesn't differ very much from the way that the Cowles Commission approach came to be applied by Klein and others. In any event $\mathrm{B}_{0}, \mathrm{~B}_{1}$ and $\Sigma$ were chosen to replicate the data as summarised in $A_{1}$ and $\Omega$.

Some restrictions must be placed upon $\mathrm{B}_{0}, \mathrm{~B}_{1}$ and $\Sigma$ in order to differentiate the shocks. Most often this is done by specifying the nature of the $\mathrm{C}_{\mathrm{j}}$ for the different types of shocks and by making the shocks uncorrelated. In his original work Sims made $B_{0}$ triangular so that $C_{0}$ also inherited that 
property. ${ }^{6}$ Such a restriction requires that one be able to identify which shocks have a non-zero contemporaneous influence on which variables e.g. money shocks might be assumed to affect output and prices only with a lag but interest rates and the exchange rate contemporaneously, and this leads to some zeros in $\mathrm{C}_{0}$. Provided the system is exactly identified, in that the number of parameters in $\mathrm{B}_{0}, \mathrm{~B}_{1}$ and $\Sigma$ is identical to that in $\mathrm{A}_{1}$ and $\Omega$, the transition from summarisation to interpretation simply involves a rotation, and the story being told cannot be invalidated using the data. There is a downside to this robustness since there are many economic model which are exactly identified and so there are many stories that would be consistent with any given data summary. Consequently, the choice between them must be made on other grounds than the ability to fit the data. In practice discrimination has generally involved judgements about the plausibility of the $C_{j}$ associated with different models.

Although one cannot deny the popularity of just identified SVAR's among academic researchers, one is left wondering about how useful they really are. Some of their popularity seems to arise from inappropriate uses of the information they supply. One often sees results being cited that have been established with a particular interpretation of the data i.e. an assumption about the nature of $\mathrm{B}_{0}$, as if these were summaries of the data. For example, it is often said that money shocks from a given SVAR system show a certain pattern for the $C_{j}$ and that this justifies an optimising behavioural model constructed by the author, even when the said model would never imply the type of $B_{0}$ that was used to find the money shocks. There is no reason at all why the $C_{j}$ found under one interpretation will hold under another i.e. the 
effects of a shock are not facts from the data but are specific to a particular interpretation of the data. All one learns from the data is the likely magnitude of the $\mathrm{C}_{\mathrm{j}}$ for a given interpretation.

Just identified SVARs have not been very popular among those involved in policy formulation. Macro models used in policy institutes are almost always over-identified and owe much more to the Cowles tradition when it comes to the specification of dynamics. It is true that their builders have adopted the principle of specifying an optimising model to produce behavioural responses that are sufficient to ensure the existence of some steady state solution path for their models, but they have been very wary of profligate dynamics being added to each structural equation to avoid 'incredible identifying assumptions'. One reason for the unpopularity of just identified SVARs in these institutes comes from the demands made on the models that are constructed. Since predictions made from (8) are identical to those from (4) $(p=1)$ there would be no reason to go through the steps to find $\mathrm{B}_{0}$ and $\varepsilon_{\mathrm{t}}$ if all one wanted to do was to produce forecasts. Any restrictions might as well be placed directly upon (4).

The other use of economic models is to conduct policy experiments but SVARs are not a good vehicle for performing that task for a number of reasons, each connected with problems involving the objects they focus on, $\varepsilon_{t}$. First, there has been some trenchant criticism, Rudebusch (1998), that the time series of estimates of $\varepsilon_{t}$ are hard to reconcile with known policy changes. Whilst unanticipated policy shocks can occur, the $\varepsilon_{\mathrm{t}}$ really measure the extent of the failure to predict $y_{t}$ from the past history of those variables included in the VAR, and thus the errors are composed of a myriad of influences other 
than policy actions. Consequently, treating the $\varepsilon_{\mathrm{t}}$ literally as policy variables is not particularly appealing. Secondly, policy generally relates directly to variables in $y_{t}$ rather than to $\varepsilon_{t}$ and it becomes torturous to try to convert policy actions into a history for $\varepsilon_{t}$.

Of the two objections to SVARs just raised, the second has less force if the series $y_{t}$ are $\mathrm{I}(1)$, since a transient change in $\varepsilon_{t}$ may now effect a permanent change in $\mathrm{yt}_{\mathrm{t}}{ }^{7}$ Moreover, a division of shocks into those that are permanent and those that are temporary can be done using the parameters of (6) i.e. from the data summary alone. Therefore, if one knows that certain shocks in a model are permanent (say those to technology), while others are only transitory, then it is possible to regard the $C_{i}$ associated with the permanent shocks as facts, in that they do not depend upon the provision of a story (except insofar as one needs to believe the names given to the permanent shocks.

\subsubsection{Academic calibrated models}

Although the SVAR approach represents a way of moving from a purely statistical model (the VAR) towards a parametric economic model that captures many characteristics of the data, it does so by using economic theory in a loose way, and relying a good deal upon a modeller's prior views of the nature of short-term adjustment mechanisms. A different tradition, rather loosely termed 'calibration' here, has taken the opposite tack of utilising economic theory in a very precise way, mostly dispensing with the objective of capturing the data generating process in any holistic way and being content just to replicate a few moments of the data. Thus, whilst these models provide a story about the macro economy, it is not necessarily one about the macro 
economy under observation. The models provide an interpretation of the data, but it is unclear how valid the interpretation is, and it is this latter caveat that has caused the most heartburn, particularly if they are to be used to shed light on policy options.

Certainly for learning about the validity of a theory and for convincing policy makers that it tells a story that is worth listening to, one needs some information upon how well the model fits the data and in what way it doesn't. A large number of procedures have emerged to do this and they can be usefully classified into three groups:

1. Methods that examine the Euler equations which are at the core of these models.

2. Methods that focus on the historical tracking record of the model.

3. Methods that aim to make inferences about selected parameters of interest robust to the fact that the calibrated model is almost certainly misspecified.

Tests of the Euler equations have either used the standard J-test for the validity of the implied moment conditions or have adopted transformations of it that may have more appeal from an economic perspective e.g. Durlauf and Hall (1990) and Durlauf and Maccini (1995) derive a 'noise ratio' index that is equivalent to studying an $\mathrm{R}^{2}$ rather than an $\mathrm{F}$ statistic (as the $\mathrm{J}$-test is). Some uses of it e.g. Konuki(1999) seem invalid as the noise ratios are compared across models, which is the equivalent of comparing $R^{2}$ with different dependent variables. Hansen et al (1997) follow a different strategy in asking how one might vary the Euler equation to satisfy the data. They do this by making the agent use risk sensitive control methods in optimisation. 
This introduces a parameter which can be used to characterise the extent to which the Euler equations of the non-risk sensitive agent fail to agree with the data.

These are numerical indices and there can be little doubt that a visual impression of how well the model fits a series of data points would be also be useful i.e. how well can (say) an RBC model reproduce the actual movements in GDP rather than just (say) the mean and variance of output growth? Tracking performance of a model was always regarded as an important piece of information in the early development of macroeconometric models and extensive graphical information was generally presented on their ability to do this. Such information was regarded as being particularly valuable when the calibrated models were dynamic.

Now let $y_{t}^{*}$ be the calibrated model output, $y_{t}$ the data, and $u_{t}=y_{t}-y_{t}{ }^{*}$ the 'model error'. Historical tracking means comparing $u_{t}$ to zero but it is rare to be able to produce a single realisation of $y_{t}^{*}$ that could be compared to $y_{t}$, since the forcing variables in most calibrated models are latent. One attempt to circumvent this difficulty has been the use of 'Solow residuals' to measure the technology shocks that enter into RBC models, but, as these are constructed from actual realisations of output, labour and capital, such an approach seems a little unsatisfactory. Such problems have led to proposals to effectively model the $u_{t}$ through a set of factors. To explore some of the issues in trying to do this take a 2 variable model that is driven by a single forcing factor $e_{t}$ (say technology) i.e. $y_{1 t}{ }^{*}=a_{1} e_{t}$ and $y_{2 t}{ }^{\star}=a_{2} e_{t}$. Now, consider a set of 'augmenting factors' $f_{1 t}$ and $f_{2 t}$, with zero means and unit variances and uncorrelated with $e_{t}$, and use these to construct the model errors. In this two 
variable case we write $y_{1 t}=a_{1} e_{t}+u_{1 t}, y_{2 t}=a_{2} e_{t}+u_{2 t}$ and then make $u_{1 t}=b_{1} f_{1 t}$, $u_{2 t}=b_{2} f_{2 t}$. Assuming that the errors are uncorrelated with $e_{t}$, one could estimate the three elements in the covariance matrix of the $u_{t}$ using the three covariances associated with $y_{1 t}$ and $y_{2 t}$. Thereafter, with a normality assumption, one can compute $E\left(u_{t} \mid y_{t}\right) .{ }^{8}$ Since $y_{t}=A E\left(e_{t} \mid y_{t}\right)+E\left(u_{t} \mid y_{t}\right)$ we have a decomposition that is useful for visual analysis.

Altug (1989) was an early contributor to this tradition. Recently, Ireland (1999) has extended the idea to allow the factors to be time-dependent. Both of these contributions fit the extended model by MLE. However, one might wish to do something a little different in estimation. Specifically, we might wish to reproduce some specified statistical features of the data e.g. in the case of a model augmented with dynamic factors we might want to reproduce (say) the moments of the VAR. The appeal of this latter strategy is that we would then just be re-interpreting the data summary in a more interesting way. Indirect estimation methods can be used to accomplish this since the auxiliary model is an easily-estimated VAR while the true model is one with latent variables that is easily simulated. Some care has to be exercised in using the approach. For example, suppose that MLE is applied with one of the parameters to be estimated being the variance of the shocks driving the calibrated model e.g. that relating to technology. Then the MLE would end up choosing $\operatorname{var}\left(e_{t}\right)=0$ and making the moments of $u_{t}$ match those of $y_{t}$. One has to either maintain a known value for var $\left(e_{t}\right)$ or, if it is to be estimated, one cannot augment the model output with a $u_{t}$ that is capable of exactly reproducing the characteristics of $y_{t}$. 
It seems unsatisfactory that the above procedures constrain $u_{t}$ and $e_{t}$ to be uncorrelated. Conceptually, the constraint might be relaxed in the following way. Suppose that the sum of the number of augmenting and calibrated model factors equals $\mathrm{n}$; in the example above, this implies a single augmenting factor $f_{1 t}$ and $y_{1 t}=a_{1} e_{t}+b_{1} f_{1 t}, y_{2 t}=a_{2} e_{t}+b_{2} f_{1 t}$. Now we might seek to estimate $b_{1}, b_{2}$ and $\operatorname{cov}\left(f_{1+} e_{t}\right)$ by choosing them to match the three elements in the covariance matrix of $y_{t}$. In this sense the factor-augmented model is exactly identified and simply re-interprets the covariance matrix of the data as the calibrated model plus extra terms that need to be added on to reproduce its covariance structure.

Finally, one might simply recognise that the calibrated model is misspecified and wish to ensure that any inferences made with it are robust to that fact. Mostly this mis-specification has been ignored e.g. Eichenbaum (1991) and Christiano and Eichenbaum (1992) effectively take $u_{t}$ to be zero and perform inferences under that assumption. Doing so allows the parameters of the calibrated model, $\theta$, to be estimated by either GMM or MLE, and 'confidence intervals' can be placed on them. Of course if the assumption is wrong we will get inconsistent estimators of the parameters and any standard errors and this will impact upon any quantities $g(\theta)$ constructed from them. Consequently, its seems important that estimators and test statistics be made robust to this mis-specification in some way.

Statistical methods to do this are given in Pagan (1994) and Diebold et al (1998). The basic idea is very simple and can be grasped with a true regression relation which contains a dependent variable $\mathrm{y}_{\mathrm{t}}$ and two independent variables $\xi_{1 \mathrm{t}}$ and $\xi_{2 \mathrm{t}}$. An investigator adopts a model ( $\mathrm{y}_{\mathrm{t}}^{*}$ ) that 
only incorporates the first of these variables. Consequently, $\mathrm{y}_{\mathrm{t}}^{*}$ involves $\xi_{1 \mathrm{t}}$ while $u_{t}$ is a function of $\xi_{2 t}$. Because we know what the true DGP is in this instance we can always figure out the consequences of the mis-specification upon any estimators of the impact of $\xi_{1 \mathrm{t}}$ upon $\mathrm{y}_{\mathrm{t}}$. In this simple case the effects of mis-specification can be found analytically, but in more general cases they need to be measured by simulating from the DGP. This latter fact suggests that we apply the same idea to calibrated models. In Pagan (1994, p. S8), I proposed such a strategy for calibrated models. The approach is simple to implement and merely requires one to select a statistical model as the DGP from which pseudo-observations can be simulated. Based on the arguments of the current paper such a model would naturally be whatever has been selected as the way of summarising the data. I did not give any examples of how the method would work, but Diebold et al (1998) do.

\subsubsection{Calibrated policy models}

In much of the discussion of the preceding section it was assumed that calibrated models are of quite small dimension. Thus, it was feasible to estimate models that are augmented by factors. However, there is another type of calibrated model used in macroeconomic research for which this would not be true. These are the relatively large calibrated models that have become increasingly popular in institutions concerned with providing advice to policymakers, see for example Black et al (1994), Black et al. (1997), Laxton et al (1998), McKibbin and Sachs (1991) and McKibbin and Wilcoxen (1995). Such models have many similarities to their academic cousins but also display significant differences. Apart from size, they place less emphasis on stochastic variation in shocks, and are concerned to make allowances for 
liquidity constrained consumers etc. in an attempt to capture actual short-run dynamic responses. One of the similarities to academic models is that many of the parameters are either chosen from a literature search or are selected to produce 'realistic' impulse responses to particular shocks. Another is that minimal attention is paid to a precise fitting of the data, with many of the models being designed to inform policy-makers through the production of a story about the economic mechanisms rather than the provision of a forecast. However, the latter requirements cannot be entirely ignored. Policy is almost always about actions based on forecasts: as has often been said inflation targeting should really be described as 'inflation forecast targeting', and so one sees models such as the Canadian and New Zealand ones mentioned above being integrated into the forecasting process.

A good example of the role of these models in leading to wisdom is their use in studying the adjustment of the world economy to the Asian crisis e.g. see McKibbin and Martin (1998) for an analysis of this event with McKibbin and Wilcoxen's (1995) calibrated G-cubed model of the world economy. Many policy institutes utilise such models for understanding some of the longer-term issues of macro policy; the exact values of variables such as output and asset prices from the simulations are rarely regarded as being as important as the insight one obtains into how the factors are likely to play out in response to a specified shock.

There are many interesting issues about how to use these models to generate wisdom and it is an area that is still under-researched. To some extent we do want to know how well they explain features of the data, and certainly we would wish to know what their failures on this score might be. 
Somehow then one needs to find relatively small models that effectively capture enough dimensions of the larger one as to effect a comparison with the data. Under certain circumstances, it is possible to utilise the output from simulations of the larger models to perform this task. Such simulations indicate what the implied impulse responses of the artificial economies embedded in the large models are to permanent and transitory shocks i.e. values of $C_{M}(L)$ in (7) and (8) can be found, where M stands for model. With this information we can then devise a VAR (or ECM) that would be capable of replicating the $\mathrm{C}_{M}(\mathrm{~L})$ to some specified degree (clearly one can never exactly represent an infinite number of $C_{j}$ with a finite order VAR).

To illustrate the methodology that might be followed consider the data set in King et al (KPSW) (1991). This contains six variables drawn from the US economy at a quarterly frequency for the years 1954:1 to 1988:4. These variables are log GDP (y), log consumption (c), log investment (i), log real money (m-p), short-run interest rate $(r)$, and the inflation rate $(\pi)$. KPSW argue that there are three permanent shocks in the data, and we take these to be productivity, nominal money and oil prices. The policy model being investigated is the McKibbin-Sachs global model (MSG2). Simulations of it were run - see Levtchenkova et al (1998) for more details- and these produce $C_{M}(1)$. From $C_{M}(1)$ one can then derive the co-integrating vectors implied by MSG2. Equations (10)-(12) show these, along with the corresponding values estimated from the data.

$$
\begin{aligned}
& c=1.04 y-.09 r+.09 \pi \quad(\text { MSG2 }) \\
& c=1.12 y-.003 r-.008 \pi \quad(\text { Data })
\end{aligned}
$$




$$
\begin{aligned}
& \mathrm{i}=1.22 \mathrm{y}-.12 \mathrm{r}+.12 \pi \quad(\mathrm{MSG} 2) \\
& \mathrm{i}=1.01 \mathrm{y}+.002 r-.002 \pi \quad \text { (Data) } \\
& \mathrm{m}-\mathrm{p}=.96 \mathrm{y}-.012 r+.052 \pi \quad(\mathrm{MSG} 2) \\
& \mathrm{m}-\mathrm{p}=1.11 \mathrm{y}-.008 \mathrm{r}+.004 \pi \quad \text { (Data) }
\end{aligned}
$$

As reported in Levtchenkova et al (1998) the MSG2 co-integrating restrictions are rejected by the data, although the point estimates look quite close. There is no doubt that the point estimates from the data are a little disconcerting, particularly the impact of real interest rates upon investment, and the conflict between the MSG2 story and the data summary raises interesting issues for quantitative analysis.

\section{CONCLUSION}

In line with the fundamental division of this paper we can ask what has been learned about the execution of the two steps of summarisation and interpretation. I think a great deal of knowledge has been accumulated through the first of these, and a consensus has emerged on useful ways of parameterising the features that we see. To some extent the consensus is stronger for univariate data, although even there one encounters questions relating to the need for non-linear structure. In the multivariate case we may not all agree on the best ways of summarising the data but important lessons have emerged along the way e.g. in the case of the US one should incorporate commodity prices into any VAR involving consumer prices. I also suspect that substantial agreement could be reached about the list of 
variables that would need to adopted to capture the essential macroeconomic data of small open economies.

The interpretation stage is much more challenging and open. It has never been hard to find stories about the data, but it has been much harder to have them formulated in such a way that they can be assessed via the data summary. In many respects the developments in macroeconomics of the past twenty years has been helpful in this regard, as there has been a strong emphasis in this literature upon producing quantitative models that are in 'realtime'. Moreover, we have seen certain theories, such as monetarism, 'monetary mis-perceptions', pure RBC theories etc. lose a lot of their appeal after many failures to adequately characterise the data. There is never a single dramatic experiment which causes this. Rather credibility is lost via repeated failures. Perhaps the biggest problem we still face in this endeavour is exactly how to perform a confrontation with the data, and it is for this reason that I have spent some time sketching what I see as some promising developments to assist us in this task. 


\section{Notes}

1 With apologies to Henry Handel Richardson.. The paper was delivered as one of the invited lectures on Macroeconomics at the $12^{\text {th }}$ World Congress of the International Economic Association in Buenos Aires, August 1999.

2 Levtchenkova et al. (1998) emphasise the distinction.

3 All of the models mentioned earlier in the text were examined in the same way as the BK model in the version of the paper given at the conference, which is available of request. The truncation was done to meet length constraints. The points made about the BK model applied to all the others as well.

4 The term $.5^{\star} \mathrm{A}_{\mathrm{l}}$ adjusts for the bias in measuring the area under the curve by a series of rectangles that are one unit in width and with the cumulated change in $y_{t}$ as length.

5 It is not clear that they can be completely divorced. Although the selection of variables to be modelled should arise naturally from what phenomenon is being studied it is likely that the set of variables selected will stem from the theories that the investigator knows about.

6 Inserting zeros only in $\mathrm{B}_{0}$ and $\Sigma$ (SVAR) rather than $\mathrm{B}_{0}$ and $\mathrm{B}_{1}$ (Cowles) is not a fundamental change in perspective.

7 Some models used in policy analysis e.g. the RIMINI model of the Bank of Norway use models with permanent shocks quite extensively.

8 In dynamic models one would use the Kalman filter for this. 


\section{References}

Altug, S. (1989) 'Time-to-Build and Aggregate Fluctuations: Some New Evidence', International Economic Review, vol. 30, pp. 889-920.

Barro, R.J. and Sala-I-Martin, X. (1995) Economic Growth (McGraw Hill).

Beaudry, P and Koop, G. (1993) ‘Do Recessions Permanently Change Output’, Journal of Monetary Economics, 31, 149-164.

Black, R., Cassino, V., Drew, A., Hansen, E., Hunt, B., Rose, D., Scott, A., (1997) 'The Forecasting and Policy System: The Core Model' (Reserve Bank of New Zealand Research Paper 43).

Black, R., Laxton, D., Rose, D., Tetlow, R., (1994) 'The steady-state model: SSQM The Bank of Canada's new Quarterly Projection Model, Part 1' (Bank of Canada Technical Report 72).

Bollerslev, T., Engle, R.F. and Nelson, D.B. (1994) 'ARCH models', in Engle R.F. and McFadden D. (eds) The Handbook of Econometrics, Vol. 4 (North-Holland).

Box, G.E.P and Jenkins, G.M. (1970) Time Series Analysis: Forecasting and Control (San Francisco: Holden-Day).

Bry, G. and Boschan, C. (1971) Cyclical Analysis of Time Series: Selected Procedures and Computer Programs (New York: NBER).

Burns, A.F. and Mitchell, W.C. (1947) Measuring Business Cycles (New York: NBER).

Chauvet, M. (1998) 'An Econometric Characterization of Business Cycle Dynamics with Factor Structure and Regime Switches', International Economic Review, vol. 39, pp. 969-96.

Chauvet, M. and Potter, S. (1998) 'Economic Turning Points and Stock Market Expectations - An Empirical Approach to the Equity Premium Puzzle' (Staff Paper, Federal Reserve Bank of New York). 
Christiano, L. and Eichenbaum, M. (1992) 'Current Real Business Cycle Theories and Aggregate Labor Market Fluctuations', American Economic Review, vol. 82 , pp. $430-50$

Cogley,T. and Nason, J. (1995) 'Output Dynamics in Real-Business-Cycle-Models', American Economic Review, vol. 85, pp. 492-511.

Cover, J.P. (1992) 'Asymmetric Effects of Positive and Negative Money Supply Shocks', Quarterly Journal of Economics, vol. 107, no. 4 (November) pp. 1261-82.

Dawes, R. (1999) 'A Message from Pyschologists to Economists: Mere Predictability Doesn't Matter Like It Should (without a good story appended to it)', Journal of Economic Behavior and Organization, vol. 39, pp. 29-40.

Diebold, F.X., Ohanian, L.E. and Berkowitz, J. (1998) ‘Dynamic Equilibrium Economies: A Framework for Comparing Models and Data', Review of Economic Studies, vol. 65, pp. 433-51.

Durlauf, S.N. and Hall, R.E. (1990) 'Bounds on the Variances of Specification Errors in Models with Expectations', Stanford University (mimeo).

Durlauf, S.N. and Maccini, L.J. (1995) 'Measuring Noise in Inventory Models', Journal of Monetary Economics, vol. 36, pp. 65-89.

Eichenbaum, M. (1991) 'Real business cycle theory: Wisdom or whimsy', Journal of Economic Dynamics and Control, vol. 15, pp. 607-21.

Engle, R. F. (1982) 'Autoregressive Conditional Heteroskedasticity with Estimates of the Variance of U.K. Inflation," Econometrica, vol. 50, pp. 987-1008.

Gallant, A.R. and Tauchen, G. (1996) 'Which moments to match?', Econometric Theory, vol. 12, pp. 657-81.

Gourieroux, C., Monfort, A. and Renault, E. (1993) 'Indirect inference', Journal of Applied Econometrics, vol. 8, pp. S85-S118. 
den Haan, W.J. and Spear, S. (1998) 'Volatility Clustering in Real Interest Rates:

Theory and Evidence', Journal of Monetary Economics, vol. 41, pp. 432-54.

Hamilton, J.D. (1989) 'A New Approach to the Economic Analysis of Nonstationary

Time Series and the Business Cycle", Econometrica, vol. 57, pp. 357-84.

Hamilton, J.D. and Jorda, O. (1997) 'A Model of the Federal Funds Rate Target', University of California at Davis (mimeo).

Hansen, L.P., Sargent, T.J. and Tallarini, T.D. (1997) 'Robust Permanent Income and Pricing', University of Chicago (mimeo).

Harding, D. and Pagan, A.R. (1998) 'Knowing the Cycle" (paper presented at the Theory and Evidence in Macroeconomics Conference at Bergamo, Italy, October 1998).

Harding, D. and Pagan, A.R. (1999) 'Dissecting the Cycle: A Methodological Investigation', Australian National University (mimeo).

Hess, G.D. and S. Iwata (1997a) 'Measuring and Comparing Business-Cycle Features', Journal of Business and Economic Statistics, vol. 15, pp. 432-44.

Hess, G.D. and Iwata, S. (1997b) 'Asymmetric Persistence in GDP? A Deeper Look at Depth', Journal of Monetary Economics, vol. 40, pp. 535-54.

Ireland, P. (1999) 'A Method for Taking Models to the Data', Boston College (mimeo).

King, R.G., Plosser, C.I., Stock, J.H. and Watson, M.W. (1991) 'Stochastic Trends and Economic Fluctuations", American Economic Review, vol. 81, pp. 819-40.

King, R.G. and Wolman, A.L. (1996) 'Inflation Targeting in a St Louis Model of the 21st Century', Federal Reserve Bank of St Louis Review, vol. 78, pp. 83-107.

Klenow, P.J. and Rodriguez-Clare, A. (1997) 'Economic Growth: A Review Essay’, Journal of Monetary Economics, vol. 40, pp. 597-617.

Konuki, T. (1999) 'Measuring Noise in Exchange Rate Models', Journal of International Economics, vol. 48, pp. 255-70. 
Koopmans,T. (1947) 'Measurement without Theory', Review of Economics and Statistics, vol. 29, pp. 161-72.

Laxton, D., Isard, P., Faruqee,H., Prasad, E. and Turtelboom, B. (1998) 'MULTIMOD Mark III: The Core Dynamic and Steady-State Models', International Monetary Fund Occasional Paper No. 164.

Levtchenkova, S., Pagan, A.R. and Robertson, J. (1998) 'Shocking Stories', Journal of Economic Surveys, vol. 12, pp., 507-532.

Lucas, R.E. (1980) 'Two Illustrations of the Quantity Theory of Money', American Economic Review, vol. 70, pp. 1005-14.

Lux, T. and Marchesi, M. (1999) 'A Micro-Simulation of Interacting Agents', University of Bonn (mimeo).

McKibbin, W. and Martin, W. (1998) 'The East Asian Crisis: Investigating Causes and Policy Responses', Australian National University (mimeo).

McKibbin, W., Pagan A.R. and Roberston, J. (1998) 'Some Experiments in Constructing a Hybrid Model for Macroeconomic Analysis', CarnegieRochester Series in Public Policy, vol. 49, pp. 113-42.

McKibbin W.J. and Sachs, J. (1991) Global Linkages: Macroeconomic Interdependence and Co-operation in the World Economy (Washington: Brookings Institution).

McKibbin, W. and Wilcoxen, P. (1995) 'The Theoretical and Empirical Structure of the G-Cubed Model', Brookings Institution Discussion Paper in International Economics, No 119.

Nelson, D.B. (1991) 'Conditional heteroskedasticity in asset returns: a new approach', Econometrica, vol. 59, pp. 347-70.

Nelson, E. (1998) 'Sluggish Inflation and Optimizing Models of the Business Cycle', Journal of Monetary Economics, vol. 42, pp. 303-22. 
Pagan, A.R. (1994) 'Calibration and Econometric Research' in Adrian Pagan (ed) Calibration Techniques and Econometrics, Journal of Applied Econometrics, vol. 9S(1994), pp. S1-S10.

Pagan, A.R. (1996) 'The Econometrics of Financial Markets', Journal of Empirical Finance, vol. 3, pp. 15-102.

Pagan, A.R. (1997) 'Towards an Understanding of Some Business Cycle Characteristics', Australian Economic Review, 30, pp. 1-15.

Pagan, A.R. (1999) 'Some Uses of Simulation in Econometrics', Mathematics and Computers in Simulation, vol. 48, pp. 341-49.

Pesaran, M.H. and Potter, S. (1997) 'A Floor and Ceiling Model of US Output', Journal of Economic Dynamics and Control, vol. 21, pp. 661-96.

Potter, S. (1995) 'A Nonlinear Approach to US GNP', Journal of Applied Econometrics, vol. 10, pp. 109-125.

Quenouille, M.H. (1957) The Analysis of Multiple Time Series (London: Griffin).

Ramey, G. and Watson, J. (1997) 'Contractual Fragility, Job Destruction and Business Cycles' Quarterly Journal of Economics, vol. 112, pp. 873-911.

Sargent, T.J. (1979) Macroeconomic Theory (New York: Academic Press).

Sichel, D. (1994) 'Inventories and the Three Phases of the Business Cycle', Journal of Business and Economic Statistics, vol. 12, pp. 269-77.

Sims, C. (1980) 'Macroeconomics and Reality', Econometrica, vol. 48, pp. 1-49.

Sims, C. (1999) 'Drifts and Breaks in Monetary Policy', (E.J. Hannan Lecture given to the Australasian Econometric Society Meetings, Sydney).

Smith, A.A. (1993) "Estimating Non-Linear Time Series Models Using Simulated Vector Autoregressions", Journal of Applied Econometrics, vol. 8, pp. S63-S84. 
Summers, L.H. (1991) 'The Scientific Illusion in Empirical Macroeconomics', in Hylleberg. S. and Paldam, M. (eds) New Approaches to Empirical Macroeconomics (Scandanavian Journal of Economics), pp. 1-20.

Zellner, A. and Palm, F. (1974) 'Time series analysis and simultaneous equation econometric models', Journal of Econometrics, vol. 2, pp. 17-54. 